\title{
Discussion on the Teaching Reform of Circuit Experiment Course
}

\author{
Yi Liu \\ College of Electrical engineering \\ Naval Univ. of Engineering \\ Wuhan, Hubei, China \\ timjoan@163.com
}

\author{
Xiang-jun Wang \\ College of Electrical engineering \\ Naval Univ. of Engineering \\ Wuhan, Hubei, China
}

\begin{abstract}
The circuit experiment course is not only an effective supplement to the circuit theory course, but also an important means to improve students' practical ability and cultivate a rigorous and realistic scientific attitude. In view of the rigid form and poor teaching effect of circuit experiment course in the past, the circuit experiment course is reformed. Firstly, it puts forward the reform plan of course arrangement which can improve students' creativity and cooperation, then optimizes the implementation process of teaching, and finally studies the assessment method which can better reflect students' learning situation. Through concrete implementation, the reform method is feasible and achieves good teaching effect.
\end{abstract}

Keywords-cooperation ability; creating competition; curriculum implementation

\section{INTRODUCTION}

Circuit course is the first professional and technical basic course for students majoring in electronic information science. It is not only necessary for students to firmly grasp the basic theoretical knowledge and basic methods of circuit, but also to cultivate students' ability of independent practice and innovation. The traditional experimental teaching mode is generally "the teacher teaches theory first, the student carries on the experiment later", lacking the experimental content and the experimental mode of the reverse process from the experimental test to the theory recursion, and the latter is more conducive to developing the students' independent exploration interest and research potential[1]. The design of traditional experiment content is mostly guided by theory, which often results in students' poor learning initiative and weak ability of independent experiment, which is not conducive to the cultivation of highly adaptable, innovative and capable Senior Electrical and electronic engineering technical personnel. With the introduction of new educational theory and system theory into the field of teaching, improving the control of teaching system has proved to be an effective way to improve teaching quality and learning efficiency[2-3].

Theoretical teaching and experimental teaching are two important components of college education. Among them, experimental teaching plays a vital role in the cultivation of practical skills and innovative ability of college students[4]. It is an important aspect that reflects the characteristics of a university. Experimental teaching reform is a systematic project involving teaching management system, experimental teaching content, experimental teaching methods, and construction of experimental teachers[5].

To solve above problems, this paper regards the cultivation of the solid basic skills and good practice spirit as the goal, after entering the university to the student's first professional basic experiment - circuit experiment, deeply analyses the reasons that restrict the teaching effect, and makes bold reforms in many aspects of experimental teaching[6-7]. Through continuous exploration and practice, a set of open management mode with strong operability and positive incentives for students has been formed, and remarkable results have been achieved.

\section{The EXISTING PROBLEMS}

In recent years, the society has paid more and more attention to technical talents with strong hands-on ability[8]. Under this circumstance, major universities have begun to pay attention to experimental courses in various disciplines and put forward many reform measures. It aims to strengthen students' initiative in the experimental class and increase students' opportunities for hands-on[9]. Especially for students to have more experimental opportunities, many schools have proposed a single-person single-group experiment. However, in the implementation of this method in recent years, some negative effects have also appeared. Mainly in the following aspects:

(1) There are a lot of students with poor grades or poor hands-on ability. During the experiment, they can't complete the experiment independently because of their own ability, so they will show the following situations:1. Keep asking the laboratory teachers, they do not use their brains to think, forming a strong dependence.2. They did not do the experiment themselves, and when the other groups finished, they directly copied the results of other people's experiments.3. Go directly to the people who have good academic performance and strong hands-on ability to see others do it, and their own equipment has been running, which reduces the utilization rate of equipment.

(2) For some basic courses or professional basic courses, there are many students studying, but the experimental teachers and fixed experimental equipment are limited. In order to allow students to experiment in a single group, the load on the laboratory is virtually doubled. The use time of the experimental equipment has increased a lot, which has accelerated the loss and aging of the experimental equipment, 
resulting in a result of a large investment, but the effect is not very good.

\section{REFORMS AND MEASURES}

\section{A. Reform of experimental course scheduling}

In response to the above-mentioned problems in the singlegroup measures in the existing reforms, I proposed a new experimental course scheduling measures, two people to do experiments, but these two must come from different professions. This new measure has the following advantages:

1) Create a competitive environment and improve the experimental results

The two experimenters come from different majors. They are of the same age and study the same course in the same school. They will certainly have a mentality that I can't lose to each other. Especially in military academies, students' sense of honor will be stronger, and they will never let other classes or district teams compare. This creates a competitive environment between two people who want to be better than each other. Driven by this mentality, they will take the initiative to preview the content of the experimental class before the experimental class, familiar with the process of the experiment; in the process of the experiment, will rush to become the leader of the experiment. This enhances students' familiarity with the experimental content and the hands-on ability in the experiment. This enthusiasm and initiative generated by the students' spontaneous self-motivation is more effective than any external incentives, which will inevitably improve the results of the experiments performed by the two students.

2) Develop students' ability to communicate and cooperate

Cooperation is one of the most popular words in the 21st century. We can hear and see every day, cooperation between the state and the country, cooperation between enterprises and enterprises, and cooperation between schools and schools. But in fact, this cooperation is cooperation between people. Therefore, we have attached great importance to the cooperation ability of a person. Whether a person can stand in a company and develop, mainly depends on the person in the first and second months of this business. In addition to watching his ability to work during this time, it is more important to look at his ability to cooperate. When a person comes to a new environment, if he has good cooperation ability, he can quickly integrate into the environment, it is easy to get help from others, then his work will go very smoothly; but if he The ability to cooperate is very poor, he will not get help from others, his work will not progress, he is doomed to fail. Quality education is now advocated, and the cultivation of cooperation ability is one of the most important parts. And this new measure can cultivate students' ability to communicate and cooperate.

There are some experiments that can't be done by one person and require the cooperation of two people. Especially now, in order to strengthen the development of independent and innovative experiments, this kind of experiments not only require students to have solid basic skills and practical ability, but also need the ability to cooperate with others. Arrange two people who don't know each other to complete the experiment together. In this way, students will have an opportunity to complete a work together with strangers. They need to discuss the experiment content, the experiment process, carry out a reasonable division of labor in the experiment process, analyze and process the experiment data together, and so on. In this way, they can cultivate their ability to communicate and cooperate with strangers through experiments. This laid the foundation for them to enter society and work smoothly with others.

3) To shorten the experiment time and increase the experiment content

Nowadays, due to the reasons of curriculum design, many courses do not have separate experimental courses, but take a small part of theoretical courses as experimental courses, so the time of experimental courses is very short. Usually only let students do a few representative experiments, many experimental students do not have the opportunity to do. With the cooperation of two people, the time of experiment can be greatly shortened by using this method. For example, it takes about two hours for students to do Kirchhoff's Theorem and Superposition Theorem in the circuit experiment when they are in a single group, but the experiment time can be controlled within one hour when they are in a group of two. In this way, other experiments can be done with the time saved. Under the condition that the total experimental time has not changed, the students have done more experiments to consolidate and learn theoretical knowledge through more experiments. At the same time, it also increases students' chances to familiarize themselves with the instruments and equipment, and has more chances to do it.

\section{B. Reform of the Implementation Process of Experimental Course}

Now the implementation process of the experiment class is generally as follows: first, the teacher introduces the content and process of the experiment; then, the students begin to do the experiment, where the students do not understand the teacher, the teacher constantly answers the questions raised by the students; finally, the students complete the experiment with the help of the teacher. The biggest problem in this implementation process is that in the process of students doing experiment, students need a lot of help from teachers. It takes a long time to complete the experiment. Teachers need to answer questions continuously, and the workload is very large. And many questions is similar, the teacher's answer is very inefficient. There are several reasons for this phenomenon:

- $\quad$ There is no preparatory before the class, students are not familiar with the experimental content. When the teacher explains it, he does not understand the content of the teacher's explanation.

- Despite the teacher's explanation and the students' preview, it is difficult for the students to connect the schematic diagram in the book with the actual components. They spend a lot of time in contacting them, which wastes a lot of time.

- The content of the teacher's explanation is too procedural and without pertinence. Teachers do not understand the students' mastery of the experiment, and can't give different explanations for different objects. 
In order to solve the problems mentioned above, I have made some reforms in the implementation process of the experiment course: take the circuit experiment as an example, first of all, ask the students to do the preview work and write the preview report before doing the experiment course; in the first 10-15 minutes of the class, let the students familiarize themselves with the experimental equipment and try to connect the physical circuit diagram, while the teacher observes the students' completion and problems, and makes spot checks experimenting the preview report; then the teacher gives the explanation of the experiment class; finally the students do the experiment.

This method has the following advantages:

- Require students to preview and improve the efficiency of the experiment. The task of preview is to find out the purpose, content, requirement, method of the experiment and the problems that should be paid attention to in the experiment, and to draw up the steps of the experiment and draw out the record form. In addition, the experimental results should be estimated so as to test the correctness of the experimental results in time. Whether the preview is adequate or not will determine whether the experiment can be successfully completed and how much is harvested.

- In the first 10-15 minutes of class, it is very important for the students to start the experiment first. First, let the students have a short time to familiarize them with the experimental equipment, so that they can better understand the experimental process when listening to the teacher's explanation, so as to improve the efficiency of the experiment. Secondly, teachers use this time to understand students' mastery of the experiment and find out the common problems of students. Thirdly, teachers use this time to conduct spot checks on students' preview reports, and record the results of the preview reports into the total scores.

- According to the observation of the students in the first 10-15 minutes of the class, the teacher explained the common problems of each student according to the previous observation besides the conventional content when explaining the experimental content. This kind of pertinent explanation can reduce the problems of students in the process of doing experiments later, and make the students' experiment process smoother and more efficient. At the same time, the teacher's answer in the back is reduced, which reduces the workload of the teacher.

- Students can better connect theory with practice through the experimental process of first doing, then listening, and then doing. They listen with questions while listening, and do experiments according to what they hear first. In this way, the effect of the experiment is better; the students can better grasp the content of the experiment and related theoretical knowledge, skilled operation of experimental instruments and equipment.

\section{Reform of the examination method of the experimental course}

Based on the cultivation of practical ability and spirit, the traditional three-stage management mode is reformed, and a comprehensive assessment system of "preview test + operation process + summary in class + final examination" is established (see table 1). In order to improve the effectiveness of various works in the experiment process, give the assessment results reflecting students' comprehensive practical ability, and guide students' behavior and habits with a scientific evaluation system.

TABLE I. Assessment AND EVALUATION SySTEM

\begin{tabular}{|c|c|c|}
\hline Examination content & Objective of examination & Proportion (\%) \\
\hline Preview test & Encourage active preview & 20 \\
\hline Operation process & Independent Operating Ability & 20 \\
\hline Summary & Summary and Analysis Ability & 10 \\
\hline Final exam & Basic Practical Skills and Theory & 50 \\
\hline
\end{tabular}

Preview test phase cancels the requirement of writing a large preview report and replaces it with preview test combined with random questions. Establish a database of preview questions; the main topic is derived from the preview thinking questions of experimental textbooks. At the beginning of the class, a preview test is taken from the question bank, which takes about three or four minutes. Teachers can roughly grasp the situation of preview by correcting on the spot, so as to make classroom management more targeted, and put pressure on students with poor preview performance to ask questions or check. The reformed method can motivate students to preview actively, facilitate teachers to master the situation of preview, and give a clear and reasonable basis for scoring. It is a highly operable means of preview inspection.

The operation process can be carried out from the following two aspects: first, classroom guidance follows the concept of "student-centered, teacher-led", encouraging students to play the leading role and think independently when facing difficulties; The second is to adopt targeted spot checks in the inspection process, which are mainly aimed at students with top practical ability and poor performance, and adjust dynamically according to students' performance.

Summary link weakens summary report, reduces repetitive copying work, and strengthens in-class summary and analysis. Let the students complete the analysis, judgment and summary of the experimental data put forward in the textbook in class. Fill in the experimental instruction book. Teachers give the summary score combined with the examination of the experimental conclusion. A few minutes are reserved before class is over. Teachers organize students to discuss and summarize, and analyze the experimental data, so as to help students connect the experimental phenomena to the theoretical basis, internalize their knowledge and sublimate their scientific understanding.

Increase the closing end-of-term examination. The paper contains two parts: operation questions and written answers. The main part is operation questions. It mainly examines the basic practical operation abilities such as line connection, instrument use and troubleshooting. 


\section{CONCLUSION}

For more than half a year, the reform of circuit experiment teaching has improved the existing problems, and the experimental effect and enthusiasm of the students have been greatly improved. At the same time, we will adopt the methods of research, practice and improvement to steadily promote the pace of reform in order to improve the quality of experimental teaching.

\section{REFERENCES}

[1] LI Wan-ping, GAO Jia-bao, and HUANG Jian-qing. "Teaching Reform and Practice of Circuit Experiment”. Education Modernization, Vol. 28, No. 7, pp. 54-56, 2017. (In Chinese)

[2] FENG Wen-hong, LIANG Gui-shu and CUI Gui-yan. "Exploration and practice of module teaching method on electrical circuit experiment”. Laboratory Science, Vol. 17, No. 1 pp. 123-125, 2014. (In Chinese)

[3] ZHANG Lin-li, LU Nian-ling and HUANG Xiao-mei. "Exploration on the construction and teaching reform of circuit experiment course". Laboratory Science, Vol. 20, No. 3 pp. 97-99, 2017. (In Chinese)
[4] LUO Xiao-juan and WU Xue. "Teaching reform and exploration of "Experiment preceding theory" in circuit experiment”. Experimental Technology and Management, Vol. 35, No. 3, pp. 216-218, 2018. (In Chinese)

[5] WANG Yong. "Reform and exploration of electronic circuit experiment teaching”. Laboratory Science, Vol. 20, No. 1, pp. 117-119, 2017. (In Chinese)

[6] WU Xiao-lin. "Improve circuit experiment teaching mode and enhance students' practical innovation ability”. Laboratory Science, Vol. 19, No. 5, pp.100-101, 2016. (In Chinese)

[7] LIN Zhi-ting. "Evaluation of integrated circuits experiment focusing on process with dynamic strategy”. Journal of Hubei Normal University, Vol. 36, No. 2, pp.80-84, 2016. (In Chinese)

[8] ZHANG Hong, XU Hui-ping, XIAO Bo and LI Kai-cheng. "Some suggestions on doing well in the teaching of circuit experiment". Experiment Science and Technology, Vol. 16, No. 2, pp.121-123, 2018. (In Chinese)

[9] LIU Ying, Wang Xiang-jun, SHAN Chao-long and LIU De-hong. "Research on circuit experiment examination based on virtual and physical experiment”. Research and Exploration in Laboratory, Vol. 32, No. 11, pp. 290-292, 2013. (In Chinese) 